Licença CC BY: Artigo distribuído sob os termos Creative Commons, permite uso e distribuição irrestrita em qualquer meio desde que o autor credite a fonte original.

\section{AS REPRESENTAÇÕES SOCIAIS DO BACHAREL EM TURISMO: FORMAÇÃ̃O, CONHECIMENTO E IDENTIDADE}

\author{
BACHELOR GRADUATES' SOCIAL REPRESENTATIONS IN TOURISM: \\ TRAINING, KNOWLEDGE AND IDENTITY
}
LAS REPRESENTACIONES SOCIALES DE LA LICENCIATURA EN TURISMO: FORMACIÓN, CONOCIMIENTO E IDENTIDAD

\section{PAULA DUTRA LEÃO DE MENEZES'}

\section{CÉLIA REGINA TEIXEIRA'}

'UNIVERSIDADE FEDERAL DA PARAÍBA, MAMANGUAPE, PARAÍBA, BRASIL.

\begin{abstract}
RESUMO: Este trabalho faz parte da tese "A construção do currículo em cursos de bacharelado em turismo: caminhos para a formação do profissional de turismo". O objetivo do presente artigo é compreender as representações sociais dos graduados como profissionais, de modo a desvendar a identidade e a realidade da formação desse profissional. A pesquisa fundamentou-se na Teoria das Representações Sociais, a qual contribui significativamente para a compreensão de fenômenos sociais. Justifica-se que o bacharel em turismo vai construindo a sua identidade profissional por meio da sua formação e das experiências e práticas cotidianas. De abordagem qualitativa, a pesquisa foi realizada com egressos dos cursos de turismo da Universidade Federal da Paraíba, da Universidade Federal de Pernambuco e Universidade Federal do Rio Grande do Norte. Como instrumento de coleta de dados foram empregadas entrevistas de grupo focal com egressos dos cursos das referidas instituições de ensino selecionadas para o estudo. Os resultados permitiram identificar as representações sociais do bacharel em turismo, como um profissional que se apresenta na noção-imagem de gestor, planejador turístico, que se materializa como a identidade profissional e emerge o discurso dos currículos prescritos nos cursos de turismo, que toma forma e configuração específica ao longo do processo de formação profissional.
\end{abstract}

PALAVRAS-CHAVE: Representações sociais; Bacharel em turismo; Formação profissional.

\footnotetext{
Paula Professora do Departamento de Turismo e Hotelaria, Universidade Federal da Paraíba, Mamanguape, Paraíba, Brasil. Doutora em Humanindades y Artes (Educação) pela Universidad Nacional de Rosario, E-mail: leaopaula@ccta.ufpb.br. Orcid: 0000-0001-9736-8802

Célia Professora da Universidade Federal da Paraíba, Mamanguape, Paraíba, Brasil. Doutora em Educação pela Pontifícia Universidade Católica de São Paulo, São Paulo, São Paulo, Brasil. E-mail: cel.teix54@gmail. com. Orcid: 0000-0002-0621-5139
} 


\begin{abstract}
This work was conducted as part of the thesis entitled Curriculum building in tourism bachelor degree courses: pathways to professional training in tourism. The objective of this article is to understand the social representations of graduates as professionals, in order to unravel the identity and reality of their education. The research was based on Theory of Social Representations, which makes a significant contribution to the understanding of social phenomena. It is justified that the bachelor in tourism builds his or her professional identity through his training and daily experiences and practices. Based on a qualitative approach, the research was conducted with graduates of tourism courses at the Federal University of Paraíba, the Federal University of Pernambuco, and the Federal University of Rio Grande do Norte. Data were collected through focus group interviews with graduates of selected courses at the above mentioned educational institutions. The results enabled us to identify the social representations of the bachelor graduate in tourism, as a professional who is presented in the notion-image of a manager, and as a tourism planner who is materialized as a professional identity, and the discourse of curricula prescribed in tourism courses emerges, which gains form shape and specific configuration throughout the vocational training process.
\end{abstract}

KEYWORDS: Social Representations; Bachelor of Tourism; Professional Training.

RESUMEN: Este trabajo forma parte de la tesis "la construcción del currículo carreras de licenciatura en turismo: caminos para la formación del profesional de turismo". El objetivo de este artículo es comprender las representaciones sociales de los graduados como profesionales para desentrañar la identidad y la realidad de su educación. La investigación se basó en la Teoría de las representaciones sociales que contribuye significativamente a la comprensión de los fenómenos sociales. Está justificado que el licenciado en turismo construya su identidad profesional a través de su formación y experiencias y prácticas diarias. Desde un enfoque cualitativo, la investigación se realizó con graduados de cursos de turismo de la Universidad Federal de Paraíba, la Universidad Federal de Pernambuco y la Universidad Federal de Rio Grande do Norte. Como instrumento de recolección de datos, se utilizaron entrevistas de grupos focales con graduados de los cursos de las instituciones educativas referidas seleccionadas para el estudio. Los resultados nos permitieron identificar las representaciones sociales de la licenciatura en turismo como profesional, se presenta en la noción de imagen de gerente, planificador de turismo, que se materializa como la identidad profesional y emerge el discurso de los planes de estudios prescritos en los cursos de turismo, que toma forma y configuración específica a lo largo del proceso de formación profesional.

PALABRAS CLAVE: Representaciones sociales; Licenciatura en Turismo; Formación profesional.

\title{
INTRODUÇÃO
}

A formação no ensino superior é o resultado de um projeto colocado em prática ao longo dos anos em uma Instituição de Ensino Superior com o objetivo de proporcionar os elementos para a atuação em uma determinada área e que tem significativa relevância no contexto de vida do sujeito.

O conjunto de atividades que caracteriza uma profissão alcança uma dimensão simbólica, referente à própria realização pessoal e ao reconhecimento social. Além disso, constitui um espaço de trocas sociais e de formação identitária (Dubar, 2012). 
Essa formação ocorre por meio da construção de conhecimentos que partem de um projeto de curso e de seus currículos, que definem os objetivos do curso, o perfil do egresso e as competências e habilidades profissionais para atuar no mercado de trabalho.

A grande questão está na formação profissional desenvolvida por meio dos currículos específicos de turismo e a sua adequação aos padrões requisitados pelo mercado de trabalho e pela sociedade para que esses profissionais capacitados atendam a tais exigências e encontrem seu lugar no mundo.

As representações sociais auxiliam nessa análise considerando que a prática profissional e a sua representação estão intimamente ligadas à sua trajetória de vida. Pode-se afirmar que o bacharel em turismo vai construindo a sua identidade profissional por meio da sua formação profissional e das experiências e práticas cotidianas.

Representações são sempre construtivas; elas constituem o mundo tal como é conhecido e as identidades que elas sustentam garante ao sujeito um lugar nesse mundo. Assim, ao serem internalizadas, as representações passam a expressar a relação do sujeito com o mundo que ele conhece e, ao mesmo tempo, elas o situam nesse mundo. É essa dupla operação de definir o mundo e localizar um lugar nele que fornece às representações um lugar simbólico (Durveen, 2013, p. 211 ).

Nesse sentido, compreender as representações sociais dos graduados como profissionais permite desvendar a identidade e a realidade da formação desse profissional e apontar os possíveis caminhos para a formação do bacharel em turismo.

\section{A FORMAÇÃO DO BACHAREL EM TURISMO: CONHECIMENTO E IDENTIDADE}

A formação e a atuação profissional do bacharel em turismo são temas que instigam docentes e profissionais da área, no entanto o tema tem sido pouco aprofundado. Ao longo desse estudo, muitas questões foram elencadas sobre o ensino superior em turismo. Sobretudo as questões que relacionam o currículo em turismo e a consequente formação do bacharel em turismo.

Para iniciar a abordagem do tema, faz necessário refletir sobre quem é o profissional formado em turismo, ou seja, o bacharel em turismo, o que ele estuda e onde ele atua. O bacharel em turismo é uma profissão que nasceu no século XX e expandiu os estudos, sobretudo em decorrência do desenvolvimento da atividade turística que cresce substancialmente no mundo, tornando-se um setor econômico significativo e fonte de renda para inúmeros países.

Esse crescimento do setor levou consequentemente à abertura de cursos superiores de turismo, inclusive na América Latina e no Brasil, para formar profissionais para trabalhar com o turismo. Muito se discute sobre esse viés da origem da formação do bacharel em turismo de ter sido de formar profissionais para atender ao mercado de trabalho. 
Formar profissionais para o mercado de trabalho não é na realidade um problema, uma vez que todo profissional visa à realização profissional, bem como a empregabilidade. Nesse aspecto, a problemática decorre em compreender quem são esses profissionais e se sua formação tem percorrido o caminho que levará a sua empregabilidade, tendo em vista que a crise que ocorre no ensino superior em turismo pode ser consequência do descompasso entre formação profissional, identidade profissional e mercado de trabalho.

Martín Duque, Gómez Bruna, Plumed Lasarte e Fernández Muñoz (2018), em análise sobre a formação em turismo na Espanha, esclarecem que existe uma grande falta de conhecimento sobre a formação em turismo, as competências adquiridas, bem como as oportunidades de carreira em vários níveis educacionais relacionado ao turismo. Entre as razões apresentadas para justificar essa situação, encontra-se a complexidade do mercado de trabalho, a consequente multidisciplinaridade dos estudos ou a relativa regulamentação recente dos estudos de turismo em comparação com outras áreas do conhecimento.

No México, Sánchez, Sánchez e Ramos (2017) abordam que as diferentes concepções sobre o turismo e as necessidades específicas das empresas turísticas geraram uma diversidade de planos de estudos, que se agruparam em uma série de disciplinas provenientes de diferentes áreas do conhecimento sem um eixo que as integre e vincule para alcançar um verdadeiro conhecimento integral do turismo, transformando em um grupo de carreiras curtas com pouca ou nenhuma especialização, dando lugar à analogia de que se forma um oceano de conhecimentos com um centímetro de profundidade. No Brasil, as Diretrizes Curriculares Nacionais para os cursos de Turismo (Parecer CNE-CES 288/2003) estabelecem o delineamento de um perfil profissional almejado para os egressos desses cursos. O perfil traçado propõe uma formação generalista e especializada para atuar no mercado com conhecimentos das ciências humanas, sociais, políticas e econômicas.

Contudo, trabalhar em turismo significa o quê? Onde? Em empresas privadas? Órgãos públicos? O que é esse mercado turístico? O setor turístico?

A resposta fundamental é o que faz o bacharel em turismo, quem é esse profissional. Pergunte a esse profissional o que ele faz e para que ele estudou e se inicia aí, talvez, o primeiro dilema desse profissional, a identidade profissional. A Lei $N^{0} 12.591 / 2012$ reconhece a profissão de bacharel em turismo e disciplina seu exercício, com as diversas atividades que o profissional pode exercer em empresas públicas e privadas.

O setor de turismo é uma atividade da iniciativa privada regulada pelo poder público. De acordo com a Lei N¹1.771/2008, art. 21, consideram-se prestadores de serviços turísticos as sociedades empresárias, as sociedades simples, os empresários individuais e os serviços sociais autônomos que prestem serviços turísticos remunerados e que exerçam as seguintes atividades econômicas relacionadas à cadeia produtiva do turismo: as empresas prestadoras de serviços turísticos são meios de hospedagem; agências de turismo; transportadoras turísticas; empresas organizadoras de eventos; parques temáticos; acampamentos turísticos. 
Neste sentido, o bacharel em turismo pode trabalhar em todas essas empresas de turismo, que possuem suas especificidades e que necessitam de conhecimentos distintos. Todavia, existem ainda outros setores e funções que o bacharel em turismo pode exercer, como o de planejamento turístico em órgãos públicos.

Medaglia e Silveira (2010) explicam que o planejamento turístico é considerado uma das principais áreas de atuação profissional dos bacharéis em turismo no Brasil. É importante salientar também que, no âmbito da educação superior de turismo, a disciplina Planejamento Turístico já era compulsória em 1971, quando o Ministério de Educação (Brasil) controlava mais firmemente os programas superiores. Na esfera pública em geral, cabe colocar ainda que o planejamento como estratégia de ação possui destaque nas Políticas Públicas Nacionais por meio dos programas lançados pelo Governo Federal.

Aqui se começa a elucidar um ponto de consenso na formação do bacharel em turismo, o de ser planejador turístico. Esse aspecto da formação parece claro para os profissionais egressos desse curso, contudo se evidencia na prática que os egressos não têm se inserido nessa área de atuação. Medaglia e Silveira (2010) pesquisaram sobre a atuação profissional dos bacharéis em turismo e o planejamento do turismo, e os resultados apontaram que $10 \%$ dos bacharéis em turismo que responderam à pesquisa mencionaram trabalhar com planejamento turístico exclusivamente ou em conjunto com outras áreas e atividades. Os autores concluem que tal constatação estaria indicando a possibilidade de o planejamento turístico ser mais promissor como área de estudo no círculo acadêmico do que como área de atuação profissional.

Retornando, então, para o setor privado, parece que são múltiplas funções que esse profissional deve estar preparado para atuar, tornando-se um super profissional. Logo, as instituições de ensino superior devem elaborar um currículo que permita formar um profissional com visão integral do Sistema Turístico, bem como também de conhecimentos específicos para exercer funções nos diversos tipos de empresas de turismo. Aí se chega a outros questionamentos, trabalhar em meios de hospedagem em quais funções? Em agência de viagens em que funções? $\mathrm{E}$ assim sucessivamente, considerando que a maioria dos postos de trabalho em turismo encontra-se em áreas operacionais.

Em pesquisa sobre a inserção no mercado de trabalho do bacharel em turismo formado no Brasil, Silva, Holanda e Leal (2018) constataram que os turismólogos atuam principalmente no setor privado, $46 \%$ predominantemente como funcionário e a maioria ocupa cargo de nível operacional, com percentual de 36,9\%. Destaca-se também os bacharéis atuam principalmente na docência e agenciamento de viagens e recebem uma remuneração mensal de um a três salários mínimos.

Por sua vez, ao discutir sobre o ensino no curso superior de turismo e as implicações para o alocamento de profissionais da área em postos de trabalho, Aranha e Rocha (2014) demonstram que existe uma infinidade de atribuições que compete ao profissional de turismo e questionam se o ensino dá subsídios para que isso aconteça na prática. De acordo com as autoras, a impressão que se tem é que o sujeito, quando se forma em turismo, tem visão de toda essa totalidade citada, mas de forma superficial, 
e a própria grade curricular pode afirmar isso. A falta de sintonia entre o mercado, o ensino em turismo e o setor público provocou queda na alocação dos profissionais de turismo no mercado e, nesse aspecto, é possível compreender um pouco o porquê do curso de turismo e de a profissão estar passando por um conflito que tem levado ao fechamento do curso em diversas faculdades e a dificuldade dos turismólogos se inserirem no mercado de trabalho.

Peres, Menezes e Teixeira (2016) enfatizam que o ensino e a aprendizagem em turismo ainda não encontraram um caminho e tem apresentado imprecisões, nesse contexto, as questões que envolvem a educação em turismo ora apontam para um caminho ora para outro, e afirmam que é imprescindível que o ensino em turismo seja discutido e trabalhado, tendo em vista que as consequências do processo de aquisição do conhecimento refletem no profissional egresso.

\section{AS REPRESENTAÇÕES SOCIAIS}

As representações sociais se apresentam como uma maneira de interpretar e pensar a realidade cotidiana e contribuem significativamente para a compreensão de fenômenos sociais, de modo que corroboram para elucidar as questões levantadas nesse trabalho.

Farr (2013) explica que o indivíduo é um agente de mudança na sociedade como é um produto dessa sociedade, a Teoria das Representações Sociais (TRS), de maneira mais adequada, defende que o indivíduo é um produto da sociedade.

Como a Teoria das Representações Sociais se articula tanto com a vida coletiva de uma sociedade como os processos de constituição simbólica, nos quais sujeitos sociais lutam para dar sentido ao mundo, entendê-lo e nele encontrar o seu lugar através de uma identidade social. (Jovchelovitch, 2013, p. 54).

Deste modo, considerando que o sujeito da pesquisa, no caso o bacharel em turismo, é produto da sociedade, que adquire uma formação profissional desenvolvida por meio dos currículos específicos, esse estudo tem o aporte na Teoria das Representações Sociais. Do ponto de vista de Farr (1998 citado por Moscovici, 2015), as representações sociais são vistas como formas de conhecimento produzidas e sustentadas por grupos sociais específicos numa determinada conjuntura histórica.

As representações sociais de Moscovicise apoiaram nos fundadores das ciências sociais na França, especialmente em Durkheim.

Moscovici afirma que a noção de representação coletiva de Durkheim descreve, ou identifica, uma categoria coletiva que deve ser explicada a um nível inferior, isto é, em nível da PSICOLOGIA SOCIAL. É aqui que surge a noção de representação social de Moscovici. Ele também julga mais adequado, num contexto moderno, estudar representações sociais do que estudar representações coletivas. O segundo conceito era um objeto de estudo mais apropriado num contexto de sociedades menos complexas, que eram do interesse de Durkheim. As sociedades 
modernas são caracterizadas por seu pluralismo e pela rapidez com que as mudanças econômicas, políticas e culturais ocorrem. Há, nos dias de hoje, poucas representações que são verdadeiramente coletivas. (Farr, 2013, p. 39).

Farr (2013) complementa que os argumentos de Moscovici possuem uma força ainda maior num contexto pós-moderno. Por sua vez, ao abordar as novas investigações, Diniz (2005) explica que o discurso da pós-modernidade é uma tentativa de lidar com o pluralismo, a diferença. Isto é, com a ideia de que todos os grupos têm o direito de falar por si mesmos, com sua própria voz, e de ter reconhecimento dessa voz como autêntica e legítima. Sendo assim, as pessoas criam representações e, segundo Moscovici (2001, p. 63), isso ocorre pela interação "em inúmeros lugares, segundo regras variadas. Dentro destes limites, o fenômeno pode ser denominado representação social".

Sobre a Teoria das Representações Sociais em estudos na área da educação, Machado (2008) elucida que desde o final da década de 1980 e início dos anos 1990, principalmente devido aos abalos vividos pela tradição positivista e cartesiana, a Teoria das Representações Sociais vêm oferecendo à pesquisa educacional novas possibilidades para lidar com a diversidade e a complexidade da educação e do contexto escolar na sociedade moderna, constituindo-se como um valioso suporte teórico para estudos nesse campo.

Gilly (1980 citado por Sousa \& Villas Bôas, 2011) assinalava, já na década de 80, que o conceito de representação social é potencialmente pertinente para a compreensão da área educacional na medida em que permite focalizar o conjunto de significações sociais presentes no processo educativo, o que não significa uma redução do campo educacional ao das representações sociais ou vice-versa.

Os currículos não podem ser concebidos como um projeto estático, mas como uma realidade em permanente construção. Estes são formados em um contexto sócio, econômico, político e ideológico construído e vivido pelos agentes envolvidos no processo de ensino e aprendizagem, ou seja, o processo educativo, de modo que a circunstância espaço e o tempo em que esses currículos são formados e materializados constituem parte do cotidiano da formação do bacharel em turismo. Desse modo, é fundamental elucidar questões sobre as raízes do curso de turismo que formam a identidade do profissional. Como é tecida essa identidade? Materializados esses currículos?

[...] precisamos compreender o mergulho no cotidiano como a incorporação da possibilidade de entender a complexidade inerente ao mundo, que tanto pode ser lido nos seus macroelementos quanto nos seus microelementos, e que jamais podem ser dissociados uns dos outros; esse mundo, no entanto, tem sido interpretado apenas a partir dos elementos compreensíveis pela observação daquilo que pode ser percebido na "pequena escala" (Oliveira, 2005, p. 62-63).

Os currículos são um produto do sistema, são delineados considerando esses macroelementos e microelementos, como macro não se pode deixar de lado as políticas educacionais de regulação das estruturas educacionais, e como micro, os 
contextos em que esses currículos são formados e materializados, em que são realizadas operações de uso, em que é tecida a formação profissional desses sujeitos, no caso, do bacharel em turismo. Barbosa (2002 citado por OLIVEIRA, 2005) afirma que o cotidiano aparece como espaço privilegiado de produção curricular para além do previsto nas propostas oficiais.

Quanto à formulação de uma proposta curricular, Oliveira (2005) explica que poderá ser portadora de um potencial emancipatório se e quando esta for fundamentada em uma epistemologia crítica e suficientemente flexível para se manter aberta às possibilidades reais dos professores que a utilizarão, respeitando-lhes os saberes e as subjetividades, bem como de seus alunos. Nesse sentido, as representações sociais se adaptam à dinâmica da sociedade, em um contexto social e de um grupo social, pois possibilita questionar e transformar. Por último, é importante destacar que Machado (2008), em estudo acerca do que se pesquisa e como se pesquisam as representações sociais no campo da educação, aponta ainda limites, sobretudo metodológicos, a serem considerados nessa produção. Todavia a autora afirma que, reconhecendo o valor heurístico da Teoria das Representações Sociais para a pesquisa no campo da Educação, bem como o caráter preliminar e provisório da análise realizada no referido estudo, não se pode nas pesquisas em educação perder de vista os famosos e formidáveis questionamentos propostos por Jodelet (2001): quem sabe e de onde sabe? O que sabe e como sabe? Sobre o que sabe e com que efeito? Tais questões apontam três pontos fundamentais a serem explorados quando se estudam representações sociais: suas condições de produção, seus processos de circulação e seu estatuto epistemológico.

Ainda sobre representações sociais, Jodelet (2001, p. 22) afirma que "são um produto e processo de uma atividade de apropriação da realidade exterior ao pensamento e de elaboração psicológica e social dessa realidade". No caso de estudos em educação, a teoria das representações sociais colabora para esclarecer inúmeras questões e, segundo Dechamps (1982 citado por Gilly, 2002), oferece um caminho para a explicação de mecanismos pelos quais fatores propriamente sociais agem sobre 0 processo educativo e influenciam seus resultados.

Moscovici (2015) argumenta que um dos propósitos das representações sociais é a tentativa de construir uma ponte entre o estranho e o familiar, tornar familiar 0 não familiar. Nesse processo se encontram a ancoragem e a objetivação. Ancorar é classificar e dar nome a alguma coisa. Coisas que não são classificadas e que não possuem nome são estranhas, não existentes e ao mesmo tempo ameaçadoras.

Pela classificação do que é inclassificável, pelo fato de dar um nome ao que não tinha nome, nós somos capazes de imaginá-lo, de representálo. De fato, a representação é, fundamentalmente, um sistema de classificação e de denotação, de alocação de categorias e nomes. (Moscovici, 2015, p. 62)

A objetivação é o momento em que o abstrato se transforma em concreto, cristalizando as ideias e tornando-as objetivas, ao que Moscovici denomina fase figurativa. 
Ancoragem e objetivação são, pois, maneiras de lidar com a memória. A primeira mantém a memória em movimento e a memória é dirigida para dentro; está sempre colocando e tirando objetos, pessoas e acontecimentos que ela classifica de acordo com um tipo e os rotula com um nome. A segunda, sendo mais ou menos direcionada para fora (para os outros), tira daí conceitos e imagens para juntá-los no mundo exterior, para fazer as coisas conhecidas a partir do que já é conhecido. (Moscovici, 2015, p. 78)

Anaya (2008) conclui que a objetivação confecciona um cenário familiar ao que outrora era desconhecido. Ocorre em duas fases: a primeira relaciona o conceito com a imagem; a segunda quando os elementos do pensamento são transpostos para a realidade, não havendo mais separação entre a representação e o objeto representado. Nesse sentido, ancoragem e objetivação são fundamentais para a construção das representações sociais.

Assim sendo, com entrevistas de grupo focal realizadas com bacharéis em turismo em cada uma das três instituições selecionadas para a pesquisa, foi verificada qual a representação social que esses graduados possuíam sobre a profissão, bem como sua representação sobre as propostas de currículos para as carreiras de graduados em turismo.

\section{METODOLOGIA}

O método adotado para a pesquisa foi qualitativo, considerando que em pesquisas sociais e humanas se revela apropriada, uma vez que permite examinar aspectos mais profundos e subjetivos do tema em estudo.

A abordagem qualitativa analisa o objeto de estudo de forma contextualizada e permite compreender a essência do fenômeno, compreender como se apresentam e são os fatos na realidade cotidiana.

Foram escolhidas para a pesquisa as seguintes instituições federais localizadas na região Nordeste do Brasil: Universidade Federal da Paraíba (UFPB), Universidade Federal do Rio Grande do Norte (UFRN) e Universidade Federal de Pernambuco (UFPE). As três instituições possuem cursos de bacharelado em turismo que foram criados em períodos bem próximos; UFPE em 1995; UFRN em 1996 e UFPB em 1998 e estão localizados na mesma região, apresentando, assim, contextos socioeconômicos e culturais bem parecidos.

Como instrumento de coleta de dados foram empregadas entrevistas de grupo focal com profissionais em turismo egressos dos cursos das referidas instituições de ensino selecionadas para o estudo. Essas entrevistas permitiram compreender as representações sociais dos graduados como profissionais, bem como o caminho que conduz a formação profissional e a identidade desse profissional.

O estudo das representações sociais constitui-se em investigações qualitativas, possuindo diversas abordagens metodológicas. Segundo Sá (1998), a Teoria das Representações Sociais não se vincula obrigatoriamente a nenhum método, o que resulta 
em opções preferenciais por diferentes métodos, sendo difícil especificar quais são os mais autorizados por cada uma das diferentes perspectivas complementares à grande teoria.

Nesse estudo utilizou-se a técnica de grupo focal. Gatti (2012) esclarece que no âmbito das abordagens qualitativas em pesquisa social a técnica de grupo focal vem sendo cada vez mais utilizada e que, em geral, pode-se caracterizar essa técnica como derivada das diferentes formas de trabalho com grupos, amplamente desenvolvidas na psicologia social.

"Grupo focal é um conjunto de pessoas selecionadas e reunidas por pesquisadores para discutir e comentar um tema, que é objetivo da pesquisa, a partir de sua experiência pessoal". (Powel \& Single citado por Gatti, 2012, p. 7).

"O trabalho com grupos focais permite compreender processos de construção da realidade por determinados grupos sociais". (Gatti, 2012, p. 11). Anaya (2008) explica que a utilização de grupo focal permite como compreender as representações sociais nas quais estão ancorados certos comportamentos, crenças, hábitos, valores, etc.

Foram realizadas três sessões, sendo cada uma com os egressos de uma determinada instituição, a amostra sendo 11 participantes na UFPB, 12 na UFPE e 8 na UFRN. Gatti (2012) orienta que o grupo focal deve ser realizado preferencialmente com grupos entre 6 e 12 pessoas.

Muitas são as possibilidades de estudos com grupo focal, entretanto é importante registrar que a técnica também apresenta limites em termos de generalizações, em função do pequeno número de participantes e da forma de seleção desses participantes ou em decorrência do menor controle do pesquisador sobre os dados que emergem das discussões nos grupos constituídos. Por outro lado, Gatti (2012) cristaliza que o trabalho com grupos focais oferece boa oportunidade para o desenvolvimento de teorizações em campo, a partir do ocorrido e falado, a riqueza do que emerge "a quente" na interpretação grupal, em geral, extrapola em muitas ideias prévias, surpreende, coloca novas categorias e formas de entendimento, que dão suporte a inferências novas e proveitosas relacionadas com o problema em exame. A forma de registro das falas do grupo focal foi a filmagem em vídeo. A referida escolha justifica-se considerando que possibilitaria o registro de toda a sessão sem interrupção das interações. Para tanto, foi elaborado também um termo de autorização para realização da filmagem. Esse termo foi apresentado aos participantes dos grupos focais e explicado que a filmagem era apenas para registrar e depois realizar as transcrições das falas, que as imagens não seriam divulgadas, que o anonimato seria garantido e autorizando a utilização das falas.

$\mathrm{Na}$ análise, os dados que emergirem das falas dos egressos e as análises foram ancorados no marco conceitual das representações sociais e do grupo focal e foram analisados pormeio do método análise de conteúdo, uma técnica de pesquisa qualitativa, conforme explica Bardin (2009), através de procedimentos objetivos e sistemáticos que descrevem o conteúdo das mensagens de comunicações extremamente variadas. As falas dos egressos são apresentadas com iniciais para que eles não sejam identificados, seguidas da instituição a que pertencem. 


\section{IDENTIDADE PROFISSIONAL DO BACHAREL EM TURISMO}

A imagem que o bacharel em turismo confere à sua identidade como profissional contém valores que se expressam em sua representação. Pimenta (1998, citado por Anaya, 2008, p. 77) elucida que uma identidade profissional se constrói a partir da significação social da profissão, a partir de seus valores, de seu modo de situar-se no mundo, de sua história de vida, de suas representações.

Tomando a perspectiva de Farr (2013), que o indivíduo é produto da sociedade, o bacharel em turismo se constitui em sujeito social que luta para dar sentido e encontrar sua identidade social e, dessa forma, as representações sociais permitem aproximar sujeito de objeto, atribuindo como estes se apropriam dessa realidade.

A identidade do bacharel em turismo parece não estar bem definida e é fundamental elucidar as questões inerentes a esse profissional tanto para o bacharel em turismo como para a sociedade.

A finalidade de todas as representações, de acordo com Moscovici (2015), é tornar familiar algo não familiar e sempre e em todo lugar. Quando se encontram pessoas ou coisas e se familiariza com elas, essas representações estão presentes.

No debate e nas reflexões realizadas pelos bacharéis em turismo emergiram muitas questões que ajudam a elucidar quem é esse profissional. No primeiro nível dos debates surgiram ideias-fonte, ou seja, noções que geram sentido primitivo. Moscovici (2015) explica que é uma questão de palavras, mas também de imagens mentais, crenças ou preconcepções. Temas conceituais podem, então, ser considerados ideiasfonte que tomam a forma de "noções", isto é, de "locais potenciais" de significado como geradores de concepções, eles são "virtuais" porque esses "locais" somente podem ser caracterizados por meio do discurso, por meio de justificações e argumentos que os "alimentam" na forma de produção de sentido.

As ideias-fonte começam a se apresentar de forma nebulosa e com algumas fissuras no que tange a essa identidade. Os egressos descreveram:

"Eu acho que a gente sai daqui sem identidade definida." (F. E., UFPB).

"Eu tenho assim duas definições que eu poderia usar. Eu sou alguém capaz de pensar criticamente sobre a atividade turística, sobretudo na cidade que eu vivo analisar os impactos positivos e negativos, como eu posso ajudar como eu posso melhorar, o que tá faltando, teria que ser crítico, reflexivo. Por outro lado, se eu for para a realidade que é atuar como turismólogo eu não sou nada. Sou mais um profissional." (A. L., UFRN).

"Depende do que você trabalha, o turismólogo pode trabalhar com muitas coisas." (L. V., UFPE).

"Eu vejo como um profissional é que vai trabalhar para a qualidade de vida, seja se ele tá trabalhando com eventos, com meio ambiente, cultura ou na parte social, eu acho que é um profissional que deve ter esse olhar despertado para a qualidade de vida das pessoas porque 0 final, o objetivo é esse." (C. M., UFPE). 
"Eu tenho uma perspectiva diferente, hoje eu não tenho mais receio e nem sinto é talvez de ficar constrangida de alguma forma em dizer que eu sou bacharel em turismo, eu já perdi isso. Então, é eu acho que eu ainda não encontrei minha identidade na área, mas eu sinto que cada vez mais há uma necessidade da gente mudar uma postura porque aqui todo mundo é capaz igual a todo mundo, a gente tem preparo e conhecimento para fazer muito melhor que muito empresário que dá estágio para a gente. Então, eu acho. É uma questão de contexto." (M.C., UFRN).

"Eu acho que falta também esse diálogo da academia de mostrar nossa identidade, não deixar a gente ficar só com essa imagem de que turismólogo vai ser sei lá camareira, recepcionista que não são profissões que não tem dignidade, não é essa visão, mas é a visão de que a gente estuda para além disso, né. Aí eu penso que deveria ter esse diálogo maior entre mercado e as pessoas responsáveis pelo curso. De uma maneira que não ficasse só na teoria fosse realmente para a prática, que a gente realmente tivesse uma coisa efetiva porque o conhecimento que a gente recebe aqui ele é super válido. Se a gente tivesse abertura para atuar no mercado, a gente poderia fazer até uma transformação no mercado turístico da cidade, mas a gente não tem essa abertura." (A. L., UFRN).

Confirma-se também nas falas que as ideias-fonte sobre a imagem do bacharel em turismo emergem e começam a se formar aliando com a sociedade e o empresariado, e proporcionam uma falta de clareza sobre a identidade. Contudo, ao longo das sessões, principiam a noção de planejador:

"Planejar, administrar, liderar." (L.V., UFPE).

"Tudo relacionado à gestão e o turismo, ter o equilíbrio entre essas áreas." (C.M., UFPE).

"Para ser planejador." (D. L., UFPB).

Constata-se regularmente o aparecimento de temas como "planejador" e, em seguida, "planejador turístico", que promulga que a noção-imagem que surge é a de gestor, planejador turístico, ou seja, a noção-imagem de planejador turístico se revela como identidade profissional dos egressos. E assim se dá início à ancoragem, que diz respeito ao processo pelo qual a ideia é trazida para o contexto familiar, que a inclui na categoria de "imagem comum".

"É como se aqui fosse um local que reunisse pessoas que planejasse uma coisa ideal, uma coisa melhor para o turismo, mas que não fosse bem a realidade, entendeu?" (C. K., UFRN).

"Nessa falta de diálogo eu acho que a gente também tem que parar de negar as nossas bases que realmente o coração do turismo, que é a da hotelaria, da agência, da consultoria, eu acho que a gente tem que realmente assumir, nós fazemos isso aqui esse é o nosso coração. E claro, eu[...] é assim não negar o coração da nossa área de trabalhar com serviços, de trabalhar com viagens, que é eu sinto que há uma negação, 
não se assume isso e é assim, eu respeito muito a sociologia eu acho que dá uma contribuição enorme, mas a gente não pratica a sociologia claro no propriamente dito, na técnica numa empresa de hotelaria, entendeu. Eu acho que tem que ter uma opção para você compreender melhor a formação, mas a gente não pode negar essa[...] e claro, não negar a nossa base e que é comercial, eu acho que a gente tá com um turismo ideário e esquecendo que é uma atividade econômica, que a gente tá na sociedade, é mercado, é comercial, é o empreendedor ganhar dinheiro e a gente tem que, a gente vai chegar lá falando de pósmodernidade daquele negócio da compreensão sobre não sei o que." (M. C., UFRN).

"Eu sou um administrador, eu sou um formador de opinião, eu sou produtor cultural, se eu sou turismólogo eu sou tudo isso, gestor, eu sou eu posso passar muito fácil por um planejador do espaço turístico." (L. V., UFPE).

"Eu acho planejador, que vai desenvolver aquele destino turístico." (R.H., UFPE).

"Eu diria planejadora, para pensar o turismo como um todo." (F. E. UFPB).

Essa identidade de pensar o turismo que se encontra em sintonia com os preceitos do planejador turístico de um destino se apresenta nas representações desses sujeitos, que direcionam:

"[...] então minha identidade como turismóloga seria essa também, é você fomentar a cultura é você divulgar seu país, é divulgar digamos é a minha posição enquanto brasileira enquanto cidadã do mundo pra pessoas[...]" (S. F., UFPB).

"[...]na identidade do turismo a gente sabe pensar o turismo, a gente sabe que a gente tem essa competência, mas enfim, o que eu acho pelo menos na realidade que eu conheço só duas pessoas que trabalham hoje com turismo, então a partir do momento que você tem essa capacidade de pensar, mas você não consegue exercer isso você acaba desvinculando isso." (D. L., UFPB).

"[...] como o curso é multidisciplinar né, a gente vê muitas disciplinas, muitas coisas diferentes durante o curso é, eu vejo essa identidade no final fazer isso né de planejar" (F. G., UFPB).

Ao abordar o tema do profissional bacharel em turismo, os egressos expõem como se identificam, ao passo que também confirmam que a sociedade ainda não compreende quem é esse profissional, e apontam para o problema relacionado ao seu posicionamento como profissional perante a sociedade, ou seja, traduzida na não institucionalização social desse profissional:

"É quando eu chegava em qualquer lugar e me apresentava como turismóloga, ah, então você é guia, né? Eu me vejo dentro do turismo na área de consultoria, planejamento e eu como turismóloga, eu me vejo assim como planejadora, como pensadora e não como guia né. E não desmerecendo o profissional de guia, mas eu estudei durante quatro anos e vejo que eu posso pensar muito mais." (C. K. UFRN). 
"[...] ah, você é turismóloga, tem gente que fala assim, ah, então você vai planejar minha viagem[...]" (F. G. UFPB).

"Você se forma e você fica como se fosse um planejador[...] faz planejamento [...] mas não existe uma profissão que você exerça isto" (P. A. UFPB).

A noção-imagem do bacharel em turismo e as representações sociais do bacharel em turismo como profissional geram temas que, no entendimento de Moscovici (2015), perduram como "imagens-conceito".

"Todos nossos discursos, nossas crenças, nossas representações provêm de muitos outros discursos e muitas outras representações elaboradas antes de nós e derivadas delas" (Moscovici, 2015, p. 242). No bojo das representações sociais do bacharel em turismo surge o discurso dos currículos prescritos nos PPC's dos cursos de turismo. Essas imagens mentais e essas crenças são concepções que, de acordo com Moscovici (2015), têm suas origens ao longo do espaço de tempo (longue durée). Nesses termos, ao longo do espaço de tempo (longue durée) da formação profissional do bacharel em turismo, solidificam-se as concepções, os princípios e as ideias propulsoras dos currículos prescritos que corroboram para as "imagens-conceito" formadas pelos egressos participantes dos grupos focais. Tal perspectiva cristaliza-se ao relacionar a formação profissional e o mercado de trabalho. Enfatiza-se que, como observado ao longo desse estudo, mais uma vez emerge essa relação, que ao longo dos grupos focais surgiu e confirmou diversas lacunas. Nesse aspecto da formação acadêmica, os egressos admitem que o mercado não almeja o conhecimento adquirido pelo bacharel em turismo e fazem um contraponto entre trabalhar em empresas privadas e órgãos públicos e, por último, assinalam para o papel do bacharel em turismo relacionando com o mercado de trabalho, como pode ser destacado nas declarações dos mesmos:

"É como se o que a gente estudasse fosse para a academia e não fosse para o mercado. O mercado pega pessoas que tem cursos variados." (C. K., UFRN).

"Eu tenho duas visões. Uma no UNP e outra aqui. Aqui não tem prática, muita teoria, teorizando, teorizando e falta prática, a onde o turismólogo vai atuar, a gente fica meio perdido. Como eu já tinha essa visão de mercado e vim para cá porque eu tinha o sonho de estudar na universidade, eu vim para cá não pelo turismo em si, mas para estudar na universidade, que eu tinha o sonho de estudar na universidade [...] Mas eu sabia do turismo, assim eu tenho maior dificuldade de trabalhar com turismo, não estou trabalhando com turismo, eu trabalho com comércio exterior, mas trabalhei muito com turismo e vi essa dificuldade da universidade de fazer a prática, de ter laboratório, de ter uma assistência maior." (H. P., UFRN).

"O mercado não valoriza o turismólogo, com todos os conhecimentos que ele adquire ao longo do curso, ele não é valorizado pelo mercado porque o mercado ele não tá querendo absorver aquele conhecimento que o turismólogo tem e adquiriu ao longo do curso, ele tá querendo só o operacional." (A. L., UFRN). 
"[...] eu acho que tá muito baseado assim o turismo muito na parte teórica, muito, muito, tanto que eu lembro que na época que eu estudava aqui, tinha um professor, professora eu não lembro bem, que focou na parte superior de turismo é mais a parte teórica e que quem quer a parte prática mesmo vai para a técnica. Então, ele achava que isso era correto, que o turismólogo ele não deveria está engajado assim em algo que era do operacional. Eu acho que tem que ser no caso os dois, uma posição assim mais técnica e uma posição mais teórica." (L. V., UFPE).

"É porque eu acho assim existem cursos de tecnólogo e existem cursos de bacharel, mas é como se eles estivessem mesmo no mesmo saco todo mundo pode fazer a mesma coisa o tecnólogo pode fazer a mesma coisa que o bacharel, mas eu acho que o bacharel ainda tem condições de fazer mais coisas que o tecnólogo. Eu fiz o curso de bacharel, mas a minha função é praticamente de tecnólogo, eu uso pouca coisa do que eu estudei aqui na universidade no meu dia a dia, então é muito a prática, eu trabalhei tanto no receptivo quanto na área de agências e todas essas questões de planejamento, de é... de administração eu uso muito pouco e isso acaba depois se perdendo também porque eu já tô a tanto tempo nessa área que eu não sei como seria passar, por exemplo, agora eu tô afim de trabalhar na EMPETUR, chegar lá e será que eu tenho todo o conhecimento, toda a parte que eu aprendi aqui, ainda tenho isso, eu não sei." (S. R., UFPE).

"[...] eu concordo é a nossa universidade ainda não prepara o aluno para o mercado de trabalho ela dá o conhecimento empírico, mas pra você sair da universidade pra trabalhar numa agência de viagem, você não saber mexer no sistema, você não vai saber mexer em nada, você vai ter só o conhecimento." (W. A., UFPB).

"Na teoria seria o que falou né, planejar, ver todos esses aspectos aí né, mas eu poderia exercer isso infelizmente somente num cargo público, mas isso não tem e daí a gente corre para o setor privado que não vai exigir todas essas questões vai se especializar numa área só." (M. M., UFPB).

"Eu não sei se todos poderiam viver isso na prática, mas na teoria essa prática do planejamento seria muito melhor no mercado de hotelaria e de agência." (A. P., UFPB).

"[...] o papel do turismólogo é esse é muito próximo do planejamento e da gestão o problema que assim a gente não tem representatividade no mercado então muitas vezes você chega numa agência de turismo e às vezes nem tem turismólogos, você chega numa secretaria de turismo não tem, no museu não tem, sabe gente concursada pela área do turismólogo. Muito do que eu vejo no curso eu poderia aplicar nesses locais mais o que sobra pra agente é agência de viagem e hotel." (D. L. UFPB).

Registra-se que Moscovici (2015) explica que temas nunca se revelam com clareza, tanto porque eles estão complexamente interligados, como também porque são combinações, iguais as representações que eles sustentam, ao mesmo tempo 
cognitivas (invariantes ancorados no aparato neurossensor e nos esquemas de ação), como culturais (universais consensuais de temas objetivados pelas temporalidades e histórias do longo espaço de tempo [longue durée]). A partir então das declarações, bem como da análise dos currículos dos cursos de turismo, revela-se que as representações sociais do bacharel em turismo são produto da interação e da comunicação que toma forma e configuração específica ao longo do processo de formação profissional. Essas representações que se formam têm repercussão direta em seu comportamento, atitudes e modos de agir, pois formam estruturas individuais de conhecimentos que informam e orientam os membros de um grupo social em determinado tempo e espaço.

Guarienti (2012) corrobora ao argumentar que, entendido como instrumento organizador do percurso formativo e profissionalizante do estudante, nota-se que as determinações curriculares abrigam espaço para a inclusão dos valores na concepção do currículo, pois ao conceber e elaborar o currículo, fazem-se escolhas, enfatizando determinados aspectos em detrimento de outros, e tais escolhas impregnam a concepção pedagógica e a linguagem no itinerário formativo do curso de turismo e, como tal, atuam não apenas àquela que se convencionou chamar de formação profissional, mas também em várias dimensões da vida do indivíduo e, por esta razão, os desdobramentos e as consequências de suas orientações participam amplamente da trajetória social global do futuro bacharel em turismo.

\section{CONSIDERAÇÕES FINAIS}

O presente estudo sobre as representações sociais do bacharel em turismo como profissionais possibilitou fazer a ponte entre o sujeito da pesquisa, desvendando sua identidade, que é resultado da formação recebida por meio dos currículos dos cursos de turismo.

A Teoria das Representação Sociais permite compreender uma realidade concebida por indivíduos e grupos construída e internalizada ao longo de espaço de tempo (longue durée). A identidade do bacharel em turismo como profissional confere uma imagem que é construída ao longo do percurso da formação profissional nas Instituições de Ensino Superior por meio dos currículos dos cursos em turismo que efetivamente são postos em prática e que os tornam produto da sociedade.

A representação social do bacharel em turismo formada pelos egressos participantes da pesquisa se apresenta primeiramente nas ideias-fonte nebulosa e com negação, em que expressam que o bacharel em turismo não possui uma identidade definida, que não encontrou a área de atuação profissional, e também, que não é para exercer determinadas funções, sobretudo operacionais em empresas do setor, a exemplo principalmente de agências de viagens e de hotelaria.

Em seguida, inicia-se o processo de tornar familiar o não familiar, a formação da imagem conceito que se materializa como identidade profissional do bacharel em turismo como planejador turístico e planejador em empresas privadas. Nesse sentido, as representações sociais do bacharel em turismo como profissional se apresentam na noçãoimagem de gestor, planejador turístico, que se materializa como a identidade profissional. 
Nesse processo, revela-se que as representações sociais são carregadas pelas concepções inerentes aos currículos dos cursos de turismo e pelos discursos dos atores (docentes) que elaboram e colocam os mesmos em prática. O discurso da competência de planejador turístico construído e disseminado no início dos cursos de turismo no país permanece atualmente difundido em concordância com as políticas educacionais (macroelementos) e pelos currículos dos cursos elaborados pelos docentes (microelementos) que foram formados sob essa perspectiva. As representações sociais dos egressos da UFPE, UFRN e UFPB sobre as propostas curriculares para as carreiras de graduados em turismo são de um turismo ideário, em pensar o turismo desvinculado à atividade profissional, muitas vezes interessante para quem decide seguir a profissão acadêmica de docente, mas que não prepara para as atividades profissionais e, portanto, são pouco utilizadas no cotidiano de trabalho.

As representações sociais são uma forma de conhecimento prático que conecta um sujeito (o bacharel em turismo) a um objeto (a formação profissional recebida por meio dos currículos dos cursos de turismo). Estas representações são produzidas e sustentadas numa determinada conjuntura histórica em que os sujeitos buscam dar sentido e se encontrar dando ao Eu um lugar no mundo (a sociedade e o mercado de trabalho), ou seja, se posicionar como ator social. Nessa premissa, ao transpor para a realidade cotidiana do bacharel em turismo, não há como dissociar representação e objeto representado. Entrelaçar a identidade profissional do bacharel em turismo com o caminho trilhado pelos egressos na formação profissional em turismo permite identificar um perfil desenvolvido por meio dos currículos específicos dos cursos que não atendem as várias dimensões desse profissional, evidenciando-se que este não encontrou o seu lugar como profissional, uma vez que, de acordo com os egressos, eles são mal compreendidos pela sociedade e pelo mercado de trabalho e, por conseguinte, acarreta em uma fragilidade profissional com repercussão na sua inserção no mercado de trabalho.

No bojo das representações sociais do bacharel em turismo, emerge o discurso dos currículos prescritos nos PPC's dos cursos de turismo, revelando que as representações sociais do bacharel em turismo são produto da interação e da comunicação, que tomam forma e configuração específica ao longo do processo de formação profissional. Surgem igualmente diversas lacunas sobre a relação entre formação profissional e mercado de trabalho. A formação profissional do bacharel em turismo produzida na atual conjuntura histórica parece assim não se sustentar mais, considerando que o perfil do bacharel em turismo não atende nem as expectativas dos egressos, nem as expectativas do mercado de trabalho e, nesse sentido, encontra-se diretamente relacionado ao atual cenário dos cursos de turismo, que apresentam significativo número de cursos com atividades encerradas e poucos alunos ingressantes. Nesse sentido, todo o exposto nesse estudo corrobora para explicar a representação social do bacharel em turismo como profissional, uma vez que, explicar uma representação, significa determinar a condição social que a originou, caracterizando e justificando a relação estrutural entre ambas. 


\section{REFERÊNCIAS BIBLIOGRÁFICAS}

Anaya, V. (2008). Prática docente e relações interpessoais: um olhar para a constituição curricular dos cursos de Pós-graduação lato sensu. Dissertação de mestrado em Educação, Pontifícia Universidade Católica de São Paulo - PUC/SP. São Paulo.

Aranha, K. C., \& Rocha, F.D.C. (2014). Reflexões acerca do ensino no curso superior de turismo: realidade, desafios e tendências. Revista Iberoamericana de turismo - RITUR. 4 (2), 67-76).

Bardin, L. (2009). Análise de conteúdo. Lisboa: Edições 70.

Brasil. Conselho Nacional de Educação. Câmara de Educação Superior. (2003). Parecer 288/2003, de 06 de novembro de 2003. Referencial para as Diretrizes Curriculares Nacionais - DCN dos cursos de graduação. Recuperado de http://portal.mec.gov.br/index.php?option=com_content\&vie $w=$ article\&id=13241:parecer-ces-2003\&catid=323:orgaos-vinculados

Brasil. Presidência da República. (2008). Lei № 11.771, de 17 de setembro de 2008. Recuperado em: 24/05/2014, de https://www.planalto.gov.br/ccivil_03/_ato2007-2010/2008/lei/l11771.htm

Brasil. Presidência da República. (2012). Lei No 12.591, de 18 de janeiro de 2012. Recuperado em: 23/05/2015, de http://www.planalto.gov.br/CCIVIL_03/_Ato2011-2014/2012/Lei/L12591.htm

Diniz, A. da S. (2005). Entre a modernidade e a pós-modernidade: novos itinerários para a sociologia. In: Diniz, A. da S., Brasileiro, M. D.S., \& Latiesa, M. (Org.) Cartografia das novas investigações em sociologia (pp.11-24). João Pessoa: EDU-UFPB / Manufatura.

Dubar, C. A (2012). Construção de si pela atividade de trabalho: a socialização profissional. Cadernos de Pesquisa, 42(146), 351-367.

Duveen, G. (2013). Crianças enquanto atores sociais: as representações sociais em desenvolvimento. En: Guereschi, P. A. \& Jovchelovich, S. (ORGs). Textos em representações sociais. (14a ed., pp. 209-238). Petrópolis: Vozes.

Farr, R. M. (2013). Representações sociais: a teoria e a história. En: Guereschi, P. A. e Jovchelovich, S. (ORGs). Textos em representações sociais. (14a ed., pp. 27-52). Petrópolis: Vozes.

Gatti, B. A. (2012). Grupo focal na pesquisa em ciências sociais e humanas. Brasília: Liber Livro editora.

Gilly, M. (2002). As representações sociais no campo educativo. In: Educar. Curitiba: Editora da UFPR. Recuperado em: 26/05/2014, de http://ojs.c3sl.ufpr.br/ojs/index.php/educar/article/ download/2092/1744.

Guarienti, M. N. (2012). A referenciação em currículos da educação profissional: os processos de discursivização e a formação em turismo. Tese de Doutorado, Faculdade de Filosofia, Letras e Ciências Humanas, Universidade de São Paulo, São Paulo. Recuperado em: 22/10/2016, de http://www.teses.usp.br/teses/disponiveis/8/8142/tde-15052013-091256/en.php

Jodelet, D. (2001). Representações sociais: um domínio em expansão. En: Jodelet, D. (Ed). As representações sociais (pp. 17-44) Rio de Janeiro: Ed.UERJ.

Jovchelovich, S. (2013). Representações sociais: a teoria e a história. En: Guereschi, P. A., \& Jovchelovich, S. (ORGs). (14a ed., pp. 53-72). Textos em representações sociais. Petrópolis: Vozes. 
Machado, L. B. (2008). Representações sociais, educação e formação docente: tendências e pesquisas nalV Jornada Internacional (pp.1-10) En:Educação emfoco. Recife. Recuperado em:22/05/2014, de http://www.fundaj.gov.br/geral/educacao_foco/representantessociaislaedamachado.pdf.

Martín Duque, Clara; Gómez Bruna, Diana; Plumed Lasarte, Marta; Fernández Muñoz, Juan José. (2018). Análisis de la formación en turismo en España: perspectiva del sector público y privado desde una aproximación cualitativa. Revista Lusófona de Educação, 38, 163-180. doi: 10.24140/ issn.1645-7250.rle38.11 Recuperado em: 20/05/2020, de http://hdl.handle.net/10437/8605

Medaglia, J., \& Silveira, C. E. (2010). Reflexões sobre a atuação profissional dos bacharel em turismos e o planejamento do turismo: pesquisa com os egressos dos Cursos de Turismo de Curitiba, Paraná, Brasil. Revista Turismo e Sociedade 3(2).

Moscovici, S. (2001). Das representações coletivas as representações sociais: elementos para uma história (pp.45-66). Em: JODELET, D. (Ed). As representações sociais. Rio de Janeiro: Ed. UERJ.

. (2015). Representações sociais: investigações em psicologia social. (1 la ed). Petrópolis: vozes.

Oliveira, I. B. de. (2005). Currículos praticados: entre a regulação e a emancipação. (2a ed.). Rio de Janeiro: DP\&A.

Peres, M. R. H. M., Menezes, P. D. L. \& Teixeira, C. R. (2016). Reflexões sobre o ensino superior em turismo no Brasil sob o enfoque das teorias psicológicas. Em: Anais do III Congresso Nacional de Educação. Natal, RN, Brasil. Recuperado em: 09/08/2017 de http://www.editorarealize.com.br/ revistas/conedu/trabalhos/TRABALHO_EV056_MD1_SA6_ID8051_25072016092554.pdf

Sá, C. P. de. (1998). A construção do objeto de pesquisa em representações sociais. Rio de Janeiro: Ed. UERJ.

Sánchez, M. de Los A. H., Sánchez, R. V., \& Ramos, J. L. L. (2017). Presente y futuro de la formación en turismo desde la perspectiva de los estudiantes de bachillerato de la región de Bahía de Banderas. Em: Educación y turismo. (orgs.) Burne, S. M. A., Pimentel, T. D. \& Léon, C. G. R. de. México: Universidad de Guadalajara. (pp. 389- 412).

Silva, L., Holanda, L., \& Leal, S. (2018). Inserção dos Turismólogos Brasileiros no Mercado de Trabalho. Revista Turismo Em Análise, 29(3), 506-524. https://doi.org/10.1 1606/issn.1984-4867.v29i3p506-524

Sousa, C. P. de, \& Villas Bôas, L. P. S. (2011). A Teoria das Representações Sociais e o estudo do trabalho docente: os desafios de uma pesquisa em rede. Rev. Diálogo Educ., 11 (33), 271-286. Curitiba.

Contribuição de cada autora na elaboração do artigo:

Paula Dutra Leão de Menezes: Pesquisadora.

Célia Regina Teixeira: Orientadora. 